\title{
Correction to: Knowledge and practices regarding infant vaccination: results of a survey of French physicians
}

\author{
Pierre Bakhache $^{1,2} \cdot$ Brigitte Virey $^{1,2} \cdot$ Christina Bienenfeld $^{3}$
}

Published online: 23 April 2019

(C) Springer-Verlag GmbH Germany, part of Springer Nature 2019

\section{Correction to: European Journal of Pediatrics (2019) 178:533-540 https://doi.org/10.1007/s00431-018-03314-3}

The above article originally published with an error present in the abstract section. Originally reading "Eight-one percent of pediatricians and $62 \%$ of GPs agreed that recommended vaccinations should become obligatory", this should instead have read "Sixty-two percent of pediatricians and $81 \%$ of GPs agreed that recommended vaccinations should become obligatory".

Publisher's note Springer Nature remains neutral with regard to jurisdictional claims in published maps and institutional affiliations.

The online version of the original article can be found at https://doi.org/ 10.1007/s00431-018-03314-3

$\triangle$ Pierre Bakhache

pbak@club-internet.fr

Brigitte Virey

bvirey@wanadoo.fr

Christina Bienenfeld

Christina.Bienenfeld@ifop.com

1 AFPA, Association Française de Pédiatrie Ambulatoire, 3 Ter Boulevard Richelieu, 02100 St-Quentin, France

2 INFOVAC, 27 rue Inkermann, 94100 Saint-Maur-des-Fossés, France

3 IFOP Healthcare, 78 rue Championnet, 75018 Paris, France 